\title{
Variability and Diversity Studies in Exotic and Indigenous Barley (Hordeum vulgare L.)
}

\author{
Banoth Vinesh*, L.C. Prasadand Ravindra Prasad \\ Department of Genetics and Plant Breeding, Institute of Agricultural Sciences \\ Banaras Hindu University, Varanasi - 221005, India \\ Corresponding author
}

\begin{tabular}{l} 
Ke y w or d s \\
Barley, Variability, \\
heritability, GCV, \\
$\begin{array}{l}\text { PCV, } \mathrm{D}^{2} \text { and } \\
\text { diversity. }\end{array}$ \\
\hline Article Info \\
\hline $\begin{array}{l}\text { Accepted: } \\
\text { 15 June } 2018 \\
\text { Available Online: } \\
10 \text { July } 2018\end{array}$ \\
\hline
\end{tabular}

\section{A B S T R A C T}

The present investigation comprising of 101 barley genotypes was conducted at Genetics and Plant Breeding, Banaras Hindu University, during rabi of 2016-17. Variability and diversity analysis was carried out based on data collected on 13 various quantitative traits. High Phenotypic coefficient of variation (PCV) and Genotypic coefficient of variation (GCV) was observed for grain yield plant, proline concentration and grain per ear. Medium PCV and low GCV values were displayed for days to heading. High heritability coupled with high genetic advance was observed for plant height, spike length, number of spikelets per spike, number of kernels per spike, kernel weight per spike, thousand kernelweight and days to 50\% flowering. These 101 barley genotypes were grouped into 12 clusters based on relative magnitude of the $\mathrm{D}^{2}$ values. The intra cluster distance was found minimum for cluster I and maximum distance in cluster VI while it was zero for cluster III, IV, V, VII, VIII, IX, X, XI and XII as these clusters consisted of only single genotype. The maximum inter-cluster distance was recorded between cluster VIII and cluster X. The cluster $\mathrm{V}$ had high mean value for flag leaf length, spike length with awn, spike length without awn and grains per ear. Cluster IV had high mean value for plant height, SPAD value; cluster III had high mean value for stomatal conductivity.

\section{Introduction}

Hordeum, Triticum and Secale belong to the tribe Triticeae, the Poaceae family. Poaceae is considered to be monophyletic; therefore all grasses belonging to this family may have evolved from a single ancestor. The genus Hordeum consists of 32 species and 45 taxa including diploid $(2 \mathrm{n}=2 \mathrm{x}=14)$, tetraploid $(2 \mathrm{n}=4 \mathrm{x}=28)$ and hexaploid $(2 \mathrm{n}=6 \mathrm{x}=42)$ cytotypes. Barley (Hordeum vulgare L.) from eating, the importance even extended to having religious significance and used in Ayurveda in India, and ritual significance in ancient Greece. It is fourth largest cereal crop after maize, wheat and rice in the world with a share of 7 per cent of the global cereal production. It is a major source of food for large population of cool and semi-arid areas of the world, where wheat and other cereals are less adapted. 
Barley is an annual cereal grain crop that is consumed as a major feed for the animals. The rest is used as malt in whiskey or sugar as well as health food. Overall India's barley production was estimated to be 1781.4 MT spread over an area of 6.93 lakh ha for the year 2016-17. The average productivity was estimated to be $25.80 \mathrm{q} / \mathrm{ha}$ (1). The positive fact about the Barley trade is the growth in the consumption over the years and the consistent increase in the production. If this pattern of consumption continues in the coming years, the exports are bound to maintain a steady uptrend as the supply is always going to lag behind the demand. Even with such a potential to become a commercial crop, in India, it always remained as poor man's crop and mostly grown with minimal inputs in marginal lands where other crops cannot survive/adapt. Hence to overcome the ill treatment it receives in the country and to compensate the minimal inputs, there is a requirement of identifying genotypes which adapt to more adverse conditions where the crop is often grown and yield to the maximum genotypic potential.

Hence, getting the genetic information about existing barley genotypes in connection with better yield and its contributing traits other argonomically important traits is need of the hour. Such information shall provide good support to barley breeders or researcher to develop the superior genotypes of varieties. Genetic variability is the back bone of crop improvement programme, effectiveness of selection depends upon nature and magnitude of genetic variability present in the genetic material. The nature and amount of genetic variability available in the germplasm indicates the scope of improvement of the character by exploiting the genetic variability. The great interest in genetic diversity arises from the possibility of demonstrating that phenotypic mean values express, in a larger or smaller degree, the genotypic value of an individual. Thus, while evaluating the divergence among populations, based on average phenotypic values, the divergence among genotypic values associated with gene frequency in different sample units (populations, varieties, clones, etc.) is also evaluated. The multivariate analysis using Mahalanobis' D2 statistic provides a useful statistical tool for measuring the genetic diversity in germplasm collections with respect to the characters considered together. It also provides a quantitative measure of association between geographic and genetic diversity based on generalized distance. Therefore, the present investigation aimed at studying variability, magnitude of coefficient of variations and diversity among 101 exotic and indigenous barley germplasm collection.

\section{Materials and Methods}

The present investigation was carried out at Genetics and Plant Breeding, Research Farm, Institute of Agricultural Sciences, Banaras Hindu University, Varanasi (U.P.) during rabiof 2016-17. Geographically, Banaras Hindu University is situated between $25^{\circ} 18^{\prime} \mathrm{N}$ latitude, $83^{\circ} 03^{\prime} \mathrm{E}$ longitudes and at an altitude of 128.93 meters above the mean sea level in the North Gangetic plain of eastern part of Uttar Pradesh. The experimental materials incorporated 101exotic and indigenous genotypes which were well-kept by BHU under All India Co-ordinated Wheat and Barley Improvement Project. Randomized Block Design with three replications was adopted for laying out the genotypes for the investigation. Each treatment (genotype) was sown in line having $2.75 \mathrm{~m}$ length with row to row and plant to plant distance of $25 \mathrm{~cm}$ and $10 \mathrm{~cm}$, respectively. All the recommended agronomic practices for respective experimental conditions were followed to raise a healthy crop. Five competitive plants, in each plot were randomly selected and tagged well in advance for recording the observations. Data was recorded on various 
yield and yield attributing traits viz.,days to 50 per cent flowering, days to maturity, flag leaf length $(\mathrm{cm})$, number of effective tillers/plant, number of grains/ear, spike length with awns $(\mathrm{cm})$, spike length without awns $(\mathrm{cm})$, stomatal conductivity (m Mol M-2 S-1), SPAD values, proline concentration ( $\mu$ mol g-1), plant height $(\mathrm{cm})$, 1000-grain weight $(\mathrm{gm})$ and grain yield/plant (gm).

Genotypic, phenotypic and environmental components of variance and their coefficient of variances (Phenotypic: PCV and Genotypic: GCV) were estimated as methods suggested by Lush (1940) and Burton (1952) respectively. The PCV and GCV values were classified as Low: Less than 10\%; Moderate: $10-20 \%$; High: More than 20\% as suggested by Sivasubramanian and Madhavamenon (1973). Heritability in broad sense [h2 (b)] was calculated according to the formulae given by Lush (1940) and categorized as Low: Less than 30\%; Medium: 30-60\%; High: More than $60 \%$ as suggested by Johnson et al. (1955).

From the heritability estimates, the genetic advance was estimated by the following formula given by Johnson et al. (1955).

$\mathrm{GA}=(\mathrm{K})(\sigma \mathrm{p}) \mathrm{h} 2(\mathrm{~b})$

Where, $\mathrm{GA}=$ Genetic advance under selection (expected); $\sigma p=$ Phenotypic standard deviation; h2 (b) = Heritability (broad sense); $\mathrm{K}=$ Selection differential at $5 \%$ selection intensity (2.06)

Genetic advance as per cent of mean was calculated as per the formula.

$\mathrm{GA}$ as per cent of mean $=(" \mathrm{GA} "$

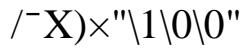

Where, $\mathrm{GA}=$ Genetic advance; ${ }^{-} \mathrm{X}=$ Grand mean of the character
The range of genetic advance as per cent of mean was classified as Low: Less than 10\%; Medium: $10-20 \%$; High: More than 20\% as suggested by Johnson et al. (1955).

Genetic diversity between genotypes was estimated by using D2 analysis given by Mahalanobis's (1936).

The D2 value between ith and jth genotypes for $P$ characters was calculated as

Dij2 = P $\Sigma t=1\left({ }^{-}{ }^{-} i t-{ }^{-}\right.$Yjt $)$

Where, ${ }^{-}$Yit $=$uncorrected mean value of ith genotype for $\mathrm{t}$ character; ${ }^{-} \mathrm{Yjt}=$ Uncorrected mean value of $\mathrm{jth}$ genotype for $\mathrm{t}$ character; $\mathrm{Dij} 2=\mathrm{D} 2$ value between ith and jth genotype.

Grouping of the genotypes into various clusters was done by using Tocher's method as described by Rao (1952)

\section{Results and Discussion}

\section{Analysis of variability}

In the present study, ANOVA of traits revealed significant variability for various traits studied in the germplsam (Table 1). Mean squares of the 13 characters from analysis of variance (ANOVA) are presented in (Table 1). Highly significant differences among genotypes $(\mathrm{P}<0.01)$ were observed for all 13 characters (days to $50 \%$ flowering, number of productive tillers per plant, spike length, spike without awn, 1000 kernel weight, grain yield plant, SPAD value, grain yield per plant days to maturity, flag leaf length, proline concentration and plant height. This result indicating that there is variability among the genotypes studied and would respond positively to selection. This finding was accordance with (8) while studied on bread wheat genotypes. Thus, it indicated that there was sufficient variability in the material 
used for their study, which provides ample scope for selecting superior and desired genotypes by the plant breeders for further improvement.

The values of GCV and PCV were very close which reinforces the greater contribution of genotype rather than environment. So the selection can be operated very well based on the phenotypic values for trait interest. The PCV was higher than the corresponding GCV for all the traits which might be due to the interaction of the genotypes with the environment to some degree or other denoting environmental factors influencing the expression of these characters.

High Phenotypic coefficient of variation (PCV) and genotypic coefficient of variation (GCV) was observed for grain yield plant, proline concentration and grain per ear which were supported by similar reports (20). The present finding is in consonance with the reports made (18); (21); (6). (4).while working with wheat, also reported that the PCV values were higher than GCV values for all the traits studied and medium PCV and GCV were showed for plant height, number of kernels per spike, 1000 kernels weight, grain yield per plot, biomass yield per plot and harvest index. Medium PCV and low GCV values were displayed for days to heading.

Moderate PCV was observed for effective tillers per plant, SPAD value, stomatal conductivity, plant height, 1000 grain weight. These finding are very similar with (3);(4). Lowest magnitude of PCV was observed for days to maturity followed by days to $50 \%$ flowering and spike length with awn and other traits exhibits medium values of PCV. The estimates of GCV and PCV were moderate for biological yield per plant, number of effective tillers per plant.

The difference between the values of PCV and GCV were high for majority of traits indicating more influence of environment in expression of these traits in both conditions. This statement conformed (20).(2) From analysis of variance found significant differences among entries for all the characters studied. The estimates of GCV and PCV were high for grain yield per plant, biological yield and number of kernels per main spike. (Table 2)

\section{Heritability (h2) and Genetic Advance (GA)}

Heritability is the heritable portion of phenotypic variance. It is a good index of the transmission of characters from parents to offspring. The estimates of heritability help the plant breeder in selection of elite genotypes from diverse genetic populations. With the help of GCV alone, it is not possible to determine the amount of variation that is heritable. The GCV together with heritability estimates would give reliable indication of the expected progress in a selection programme (15). High heritability percentage coupled with high genetic variability particularly grain yield per plant under normal situation and emerged as an ideal traits for improvement through simple selection in upcoming generations.

In the present investigation, high heritability estimates were obtained for all the thirteen quantitative traits studied (Fig. 1). Broad sense heritability estimate was highest for days to $50 \%$ flowering, grain yield per plant, plant height, stomata conductivity and grain per ear. These finding were in accordance with the findings of (13).

However, heritability values alone may not provide clear predictability of the breeding value. Heritability in conjugation with genetic advance over mean is more effective and reliable in predicting the effectiveness of selection. In the present experiment, all the characters studied had exhibited high heritability coupled with high genetic advance 
as percentage of mean. Estimates of high heritability and high genetic advance together may be ascribed to the conditioning of the characters by additive effect of the polygene's which could be improved upon by adopting selection without progeny testing.

High heritability coupled with high genetic advance was observed for plant height, spike length, number of spikelet's per spike, number of kernels per spike, kernel weight per spike, thousand kernel-weight and days to $50 \%$ flowering, these findings were supported by earlier reports of (14) and (20).

Genetic advance as percentage of mean was highest for grain yield per plant and proline concentration. Similar reports were reported (15). High heritability coupled with high genetic advance as percentage of mean was found for grain yield per plant followed by grain per ear (Fig. 1). These findings were in consonance with earlier reports made (10);(9).

\section{Analysis of genetic diversity}

The multivariate analysis using Mahalanobis D2 statistics is a valuable tool for obtaining quantitative estimates of divergence between biological populations. For an effective and informative breeding programme, information concerning the extent and nature of genetic diversity within a crop species is essential to researchers.

Assessment of genetic diversity was made based on the data recorded for thirteen traits on hundred and one barley genotype using Tocher's D2 analysis. Using this method a set of 101 barley genotypes were grouped into 12 clusters based on relative magnitude of the D2 value. Cluster I comprised of 47, Cluster II 29, Cluster VI 16 genotypes each. Cluster such as III, IV, V, VII, VIII, IX, X, XI and XII had one genotype each (Table 3 ).

\section{Inter and Intra cluster $D^{2}$ values:}

The intra cluster distance was found minimum for cluster I and maximum distance in cluster VI while it was zero for cluster III, IV, V, VII, VIII, IX, X, XI and XII as these clusters consisted of only single genotype (Table 4). The inter cluster distance was minimum between cluster $\mathrm{V}$ and cluster III indicating close relationship and similarity for most of the character of barley genotype falling in these cluster. The maximum inter-cluster distance was recorded between cluster VIII and cluster $\mathrm{X}$ followed by cluster $\mathrm{V}$ and IX and cluster IV and IX. Suggesting highest genetic divergence existing between the genotypes of these clusters.

\section{Cluster means of various characters studied}

The cluster mean values for different characters indicated differences between the clusters for all the traits studied (Table 5). The cluster $\mathrm{V}$ had high mean value for flag leaf length, spike length with awn, spike length without awn and grains per ear. Cluster IV had high mean value for plant height, SPAD value; cluster III had high mean value for stomatal conductivity.

Cluster VI had high mean for 1000 grain weight; cluster XI had maximum value for proline concentration. Cluster $\mathrm{X}$ had highest value for days to maturity and cluster XII had high value for days to $50 \%$ flowering it had lowest value for proline concentration. The result indicates that selection of genotypes having high values for particular trait could be made and used in the hybridization programme for improvement of that character. Grain yield per plant, days to 50\% flowering, stomatal conductivity, plant height and flag leaf length had highest relative contribution towards divergence followed by days to $50 \%$ flowering and stomatal conductivity. 
Table.1 Analysis of variance (ANOVA) for thirteen quantitative traits in 101 barley genotypes

\begin{tabular}{|c|c|c|c|c|c|c|c|c|c|c|c|c|c|c|}
\hline \multirow{2}{*}{$\begin{array}{l}\text { Source of } \\
\text { variation }\end{array}$} & \multirow[t]{2}{*}{ Df } & \multicolumn{13}{|c|}{ Mean Sum of Squares } \\
\hline & & DF & DM & FL & ET & SPAD & SC & PC & SL & SLW/O & $\mathbf{P H}$ & $\mathbf{G} / \mathbf{E}$ & GW & GY \\
\hline Replication & 2 & 2.08 & 7.76 & 0.61 & 1.57 & 14.56 & 75.185 & 2.40 & 1.58 & 0.55 & 25.78 & 0.18 & 0.36 & 1.70 \\
\hline Treatment & 100 & $137.90^{* *}$ & $67.64^{* *}$ & $26.54^{* *}$ & $6.61^{* *}$ & $43.27^{* *}$ & $23973.16^{* *}$ & $62.60^{* *}$ & $5.64^{* *}$ & $3.52^{* *}$ & $435.42^{* *}$ & $398.70^{* *}$ & $168.51^{* *}$ & $50.55^{* *}$ \\
\hline Error & 200 & 2.08 & 3.17 & 0.73 & 1.11 & 10.15 & 474.33 & 2.49 & 2.08 & 0.28 & 5.78 & 9.67 & 8.01 & 0.91 \\
\hline \multirow{2}{*}{$\begin{aligned} \text { Range } & \text { Min. } \\
& \text { Max. }\end{aligned}$} & & 62.33 & 97 & 6.39 & 5.96 & 37.40 & 313.97 & 8.61 & 17.44 & 5.03 & 63.11 & 9.00 & 25.53 & 3.53 \\
\hline & & 97.00 & 119.33 & 25.59 & 13.78 & 54.33 & 662.93 & 27.61 & 23.16 & 10.26 & 117.56 & 61.00 & 58.70 & 24.41 \\
\hline Grand Mean & & 78.25 & 113.30 & 14.75 & 9.59 & 45.82 & 485.35 & 14.71 & 20.13 & 7.35 & 93.53 & 39.02 & 40.24 & 12.93 \\
\hline $\mathrm{SE}( \pm)$ & & 0.83 & 1.03 & 0.49 & 0.61 & 1.84 & 12.57 & 0.91 & 0.83 & 0.31 & 1.72 & 1.80 & 1.63 & 0.55 \\
\hline
\end{tabular}

${ }^{* * *}$ Significant at $\mathrm{p}<0.01$.

$\mathrm{DF}=$ Days to $50 \%$ flowering, FL=flag leaf length, ET=effective tillers/plant, SPAD, SC=stomatal conductivity, PC=proline concentration, SL=splike length with awn, $\mathrm{SLW} / \mathrm{O}=$ =spike length without awn, $\mathrm{PH}=$ plant height, $\mathrm{G} / \mathrm{E}=$ grain per ear, $\mathrm{GW}=1000$ grain yield, $\mathrm{DM}=$ days to maturity, $\mathrm{GY}=$ grain yield 
Table.2 Variability parameters for 13 quantitative characters in 101 barley genotypes. (Early sown condition)

\begin{tabular}{|c|c|c|c|c|c|c|c|c|c|c|c|c|c|}
\hline Trait & $\mathrm{DF}$ & DM & FL & $\mathrm{ET}$ & SPAD & $\mathrm{SC}$ & $\mathrm{PC}$ & SL & SLW/O & $\mathrm{PH}$ & $\mathrm{G} / \mathrm{E}$ & GW & GY \\
\hline Range Min. & 62.33 & 97 & 6.39 & 5.96 & 37.40 & 313.97 & 8.61 & 17.44 & 5.03 & 63.11 & 9.00 & 25.53 & 3.53 \\
\hline Max. & 97.00 & 119.33 & 25.59 & 13.78 & 54.33 & 662.93 & 27.61 & 23.16 & 10.26 & 117.56 & 61.00 & 58.70 & 24.41 \\
\hline Grand Mean & 78.25 & 113.30 & 14.75 & 9.59 & 45.82 & 485.35 & 14.71 & 20.13 & 7.35 & 93.53 & 39.02 & 40.24 & 12.93 \\
\hline SE $( \pm)$ & 0.83 & 1.03 & 0.49 & 0.61 & 1.84 & 12.57 & 0.91 & 0.83 & 0.31 & 1.72 & 1.80 & 1.63 & 0.55 \\
\hline PCV $(\%)$ & 8.79 & 4.38 & 20.71 & 17.92 & 10.03 & 18.78 & 32.27 & 8.99 & 15.90 & 13.14 & 30.25 & 19.49 & 32.31 \\
\hline GCV (\%) & 8.60 & 4.09 & 19.88 & 14.12 & 7.23 & 18.24 & 30.43 & 5.41 & 14.15 & 12.75 & 29.18 & 18.17 & 31.45 \\
\hline $\begin{array}{l}h^{2} \% \text { (broad } \\
\text { sense) }\end{array}$ & 96 & 87 & 92 & 62 & 52 & 94 & 89 & 36 & 79 & 94 & 93 & 87 & 95 \\
\hline $\begin{array}{l}\text { GA as \% of } \\
\text { mean }(5 \%)\end{array}$ & 17.32 & 7.87 & 39.31 & 22.93 & 10.73 & 36.48 & 59.11 & 6.70 & 25.94 & 25.48 & 57.99 & 34.92 & 63.05 \\
\hline $\begin{array}{l}\text { GA as } \% \text { of } \\
\text { mean }(1 \%)\end{array}$ & 22.20 & 10.08 & 50.38 & 29.38 & 13.75 & 46.75 & 75.75 & 8.59 & 33.24 & 32.65 & 74.32 & 44.75 & 80.80 \\
\hline
\end{tabular}

$\mathrm{DF}=$ Days to $50 \%$ flowering, FL=flag leaf length, ET=effective tillers/plant, SPAD, SC=stomatal conductivity, $\mathrm{PC}=$ proline concentration, $\mathrm{SL}=$ splike length with awn, SLW/O=spike length without awn, $\mathrm{PH}=$ plant height/E=grain per ear, $\mathrm{GW}=1000$ grain yielded= days to maturity, $\mathrm{GY}=$ grain yield 
Table.3 Cluster pattern of 101 barley genotypes for thirteen quantitative character (Tocher's Method)

\begin{tabular}{|c|c|c|}
\hline Clusters & Germplasm Lines/Genotypes & Number \\
\hline I & 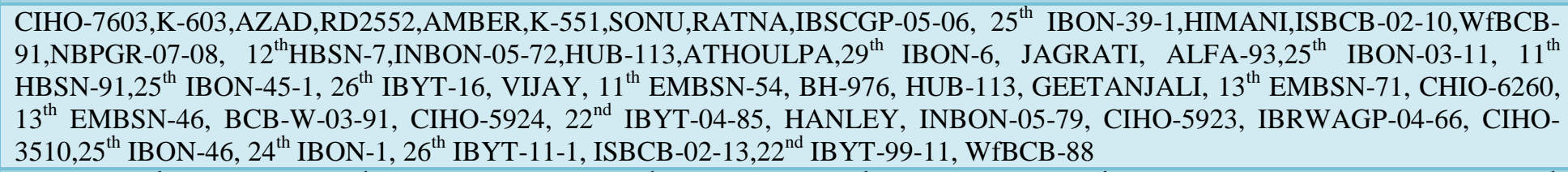 & 47 \\
\hline II & 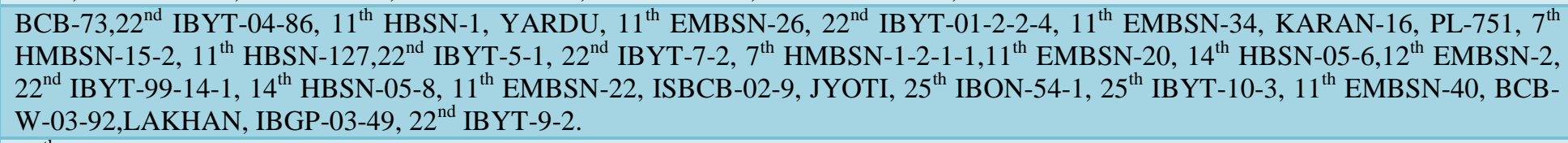 & 29 \\
\hline III & $11^{\text {th }} \mathrm{HBSN}-175$ & 1 \\
\hline IV & CANUT & 1 \\
\hline V & MARRIA & 1 \\
\hline VI & $\begin{array}{l}11^{\text {th }} \text { EMBSN-37-1, 25 } 5^{\text {th }} \text { IBON-11, INBON-07-08-71, HUB-180, } 25^{\text {th }} \text { IBON-03-6, HARMAL,BEECHER, } 24^{\text {th }} \text { IBON-40-1, } 11^{\text {th }} \text { EMBSN- } \\
23 \text {, HORMAL, MOROC-9-75, PL-825, V-MORALES, INBON-05-50, RD-2715, CIHO-8355. }\end{array}$ & 16 \\
\hline VII & IBGP-03-65 & 1 \\
\hline VIII & $26^{\text {th }}$ IBYT-49 & 1 \\
\hline IX & $11^{\text {th }}$ EMBSN-47-03 & 1 \\
\hline $\mathrm{X}$ & INBON-07-08-8 & 1 \\
\hline XI & $11^{\text {th }}$ EMBSN-21 & 1 \\
\hline XII & $22^{\text {nd }}$ IBYT-7 & 1 \\
\hline
\end{tabular}


Table.4 Average Intra (bold) \& Inter ClusterD ${ }^{2}$ Distances of thirteen characters (Tocher's Method)

\begin{tabular}{|c|c|c|c|c|c|c|c|c|c|c|c|c|}
\hline $\mathbf{O P}$ & I & II & III & IV & $\mathbf{V}$ & VI & VII & VIII & IX & $\mathbf{X}$ & XI & XII \\
\hline I & 45.477 & 90.701 & 67.306 & 64.000 & 92.211 & 87.358 & 90.789 & 182.252 & 208.496 & 166.689 & 144.476 & 182.286 \\
\hline II & & 70.133 & 167.996 & 162.819 & 212.251 & 149.188 & 127.813 & 112.010 & 118.110 & 162.185 & 117.306 & 143.668 \\
\hline III & & & 0.000 & 42.630 & 24.249 & 80.951 & 169.497 & 249.191 & 303.474 & 292.057 & 250.860 & 315.156 \\
\hline IV & & & & 0.000 & 55.083 & 95.300 & 86.060 & 301.883 & 367.418 & 202.165 & 193.257 & 234.050 \\
\hline V & & & & & 0.000 & 105.183 & 173.372 & 318.586 & 377.955 & 310.225 & 316.305 & 333.909 \\
\hline VI & & & & & & 72.242 & 173.350 & 240.535 & 267.430 & 222.168 & 202.957 & 278.204 \\
\hline VII & & & & & & & 0.000 & 290.522 & 334.476 & 117.031 & 138.902 & 101.603 \\
\hline VIII & & & & & & & & 0.000 & 28.500 & 389.275 & 178.244 & 301.653 \\
\hline IX & & & & & & & & & 0.000 & 353.094 & 208.906 & 286.432 \\
\hline$X$ & & & & & & & & & & 0.000 & 180.587 & 80.644 \\
\hline XI & & & & & & & & & & & 0.000 & 247.391 \\
\hline XII & & & & & & & & & & & & 0.000 \\
\hline
\end{tabular}


Table 5. Mean values of clusters for thirteen quantitative traits (Tocher's method)

\begin{tabular}{|c|c|c|c|c|c|c|c|c|c|c|c|c|c|}
\hline Clusters & DF & DM & FL & ET & SPAD & SC & PC & SL & SLW/O & PH & G/E & GW & GY \\
\hline I & 78.624 & 115.262 & 14.832 & 9.633 & 45.924 & 484.035 & 13.649 & 20.316 & 7.605 & 98.734 & 42.645 & 40.290 & 14.219 \\
\hline II & 77.770 & 110.034 & 14.110 & 9.124 & 44.759 & 440.594 & 15.444 & 19.416 & 6.730 & 82.445 & 30.540 & 36.048 & 9.897 \\
\hline III & 75.333 & 116.000 & 15.220 & 11.067 & 46.367 & 611.533 & 13.610 & 19.867 & 8.177 & 99.110 & 58.000 & 42.333 & 20.827 \\
\hline IV & 87.000 & 117.333 & 12.833 & 9.557 & 52.233 & 545.633 & 15.333 & 21.333 & 7.057 & 105.447 & 53.000 & 47.867 & 19.830 \\
\hline V & 77.667 & 113.333 & 19.890 & 9.780 & 47.567 & 555.200 & 15.687 & 22.333 & 9.833 & 104.110 & 60.667 & 45.033 & 23.407 \\
\hline VI & 76.083 & 114.083 & 15.887 & 10.322 & 46.877 & 578.238 & 15.968 & 20.909 & 7.720 & 100.481 & 45.313 & 49.081 & 14.664 \\
\hline VII & 94.333 & 117.333 & 14.787 & 11.330 & 50.400 & 356.333 & 15.760 & 18.267 & 7.643 & 104.553 & 41.000 & 26.900 & 13.563 \\
\hline VIII & 64.000 & 99.333 & 10.543 & 7.887 & 43.000 & 365.833 & 18.207 & 19.853 & 5.813 & 64.557 & 33.667 & 34.867 & 11.510 \\
\hline IX & 62.333 & 98.000 & 13.603 & 6.333 & 40.733 & 415.667 & 11.390 & 20.277 & 5.623 & 65.890 & 18.333 & 31.933 & 7.993 \\
\hline X & 96.000 & 118.667 & 18.500 & 10.557 & 49.033 & 549.180 & 14.463 & 19.870 & 8.213 & 93.667 & 20.000 & 45.410 & 3.533 \\
\hline XI & 82.000 & 113.333 & 6.387 & 9.957 & 46.833 & 466.200 & 26.703 & 21.230 & 7.053 & 104.000 & 13.333 & 34.500 & 6.230 \\
\hline XII & 97.000 & 116.000 & 17.900 & 9.387 & 45.400 & 375.833 & 9.573 & 17.767 & 6.830 & 65.777 & 28.000 & 31.533 & 9.537 \\
\hline
\end{tabular}

$\mathrm{DF}=$ Days to $50 \%$ flowering, $\mathrm{FL}=$ flag leaf length, $\mathrm{ET}=$ effective tillers/plant, $\mathrm{SPAD}, \mathrm{SC}=$ stomatal conductivity, $\mathrm{PC}=$ proline concentration, $\mathrm{SL}=$ splike length with awn, SLW/O=spike length without awn, $\mathrm{PH}=$ plant height/E=grain per ear, $\mathrm{GW}=1000$ grain yielded= days to maturity, $\mathrm{GY}=$ grain yield 
Fig 1. Genetic parameters of 13 quantitative characters in 101 barley genotypes

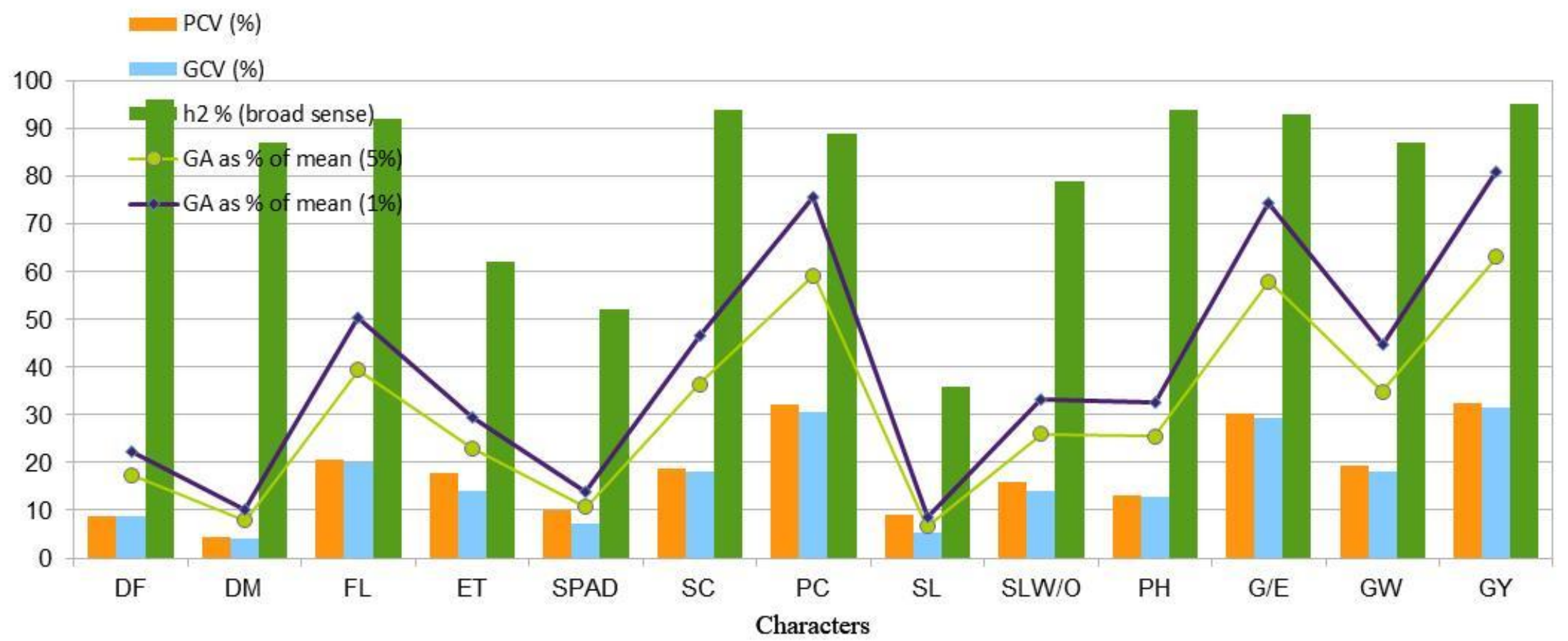

$\mathrm{DF}=$ Days to $50 \%$ flowering, $\mathrm{FL}=$ flag leaf length, $\mathrm{ET}=$ effective tillers/plant, $\mathrm{SPAD}, \mathrm{SC}=$ stomatal conductivity, $\mathrm{PC}=$ proline concentration, $\mathrm{SL}=$ splike length with awn, $\mathrm{SLW} / \mathrm{O}=$ spike length without awn, $\mathrm{PH}=$ plant height, $\mathrm{G} / \mathrm{E}=$ grain per ear, $\mathrm{GW}=1000$ grain yield, $\mathrm{DM}=$ days to maturity, $\mathrm{GY}=$ grain yield 


\section{References}

1. Anonymous (2017). Progress Report of All India Coordinated Research Project on Wheat \& Barley 2016-17, Vol. VI. Barley Network. ICARIndian Institute of Wheat and Barley Research, Karnal, India. P. 280.

2. Al-Tabbal, J., Al-Fraihat., Alimad, H. (2012). Genetic Variation, Heritability, Phenotypic and Genotypic Correlation Studies for Yield and Yield Components in Promising Barley Genotypes. Journal of Agricultural Science, 4 (I 3):193.

3. Binod, K., Singh, C.M., Jaiswal. K.K (2013). Genetic variability, association and diversity studies in bread wheat (Triticum aestivum L.). The Bio scan, 8(1): 143-147.

4. Birhanu M., Sentayehu, A., Alemayehu, A., Ermias, A. and Dargicho, D. (2016). Genetic Variability, Heritability and Genetic Advance for Yield and Yield Related Traits in Bread Wheat (Triticum aestivum L.) Genotypes. Global Journal of Science Frontier Research, 16 (7).

5. Burton, G.W. (1952). Quantitative inheritance in grasses. Proc. 6th Int. Grasslands Cong. J.,1:227-283.

6. Jalal A. Al-Tabbal (2012). Genetic Variation, Heritability, Phenotypic and Genotypic Correlation Studies for Yield and Yield Components in Promising Barley Genotypes. Journal of Agricultural Science, 4 (3).

7. Johnson, H.W., Robinson, H.F. and Comstock, R.E. (1955). Estimation of genetic variability and environmental variability in soybean. Agron. J., 47: 314-318.

8. Kalimullah, S. J. Khan, M. Irfaq and H. U. Rahman, 2012. Genetic variability, correlation, and diversity studies in bread wheat (Triticum aestivum L.) germplasm. The Journal of Animal \& Plant Sciences, 22(2), Page: 330-333, Khan, Pakistan.

9. Kumar, M., Shekhawat, S.S. (2013). Correlation and path coefficient studies in barley (Hordeum vulgare L.) under dual purpose condition. Electronic Journal of Plant Breeding, 4 (4):1313-1318.

10. Lodhi, R.D., Prasad, L.C., Madakemohekar, A.H., Bornare S., Prasad, R. (2015). Study of Genetic parameters for yield and yield contributing trait of elite genotypes of barley (Hordeum vulgare L.). Indian Research Journal of Genetics and Biotechnology,7 (1): 17-21.

11. Lush, J.L. (1940). Intra-sire correlation and regression of offspring on dams as a method of estimating heritability of characters. In: Proc. of "American Society of Animal Production”. 33: 293-301.

12. Mahalanobis, P.C. (1936). On the Generalized Distance in Statistics. Proceedings of the National Institute of Science of India, 2 (4): 49-55.

13. Navin, K., Markar, S., Vijay, K., Sunil. (2014). Studieson heritability and genetic advance estimates in timely sown bread wheat (Triticum aestivum L.).Bioscience Discovery,5 (1):64-69.

14. NecdetAkgun (2016). Genetic Variability and Correlation Studies in Yield and Yield Related Characters of Barley (Hordeum vulgare L.) Genotypes. Journal of Agriculture Food Science, 30 (2): 88-95.

15. Raikwar, R.S., Upadhyay, A.K., Tyagi, P.K. (2014). Heritability and genetic variability for yield components under two regimes of soil in barley (Hordeum vulgare L.). The Bioscan, 9 (4): 1613-1617.

16. Rao, C.R. (1952). Advanced Statistical Methods in Biometrical Research. 
New York: John Willey and Sons Inc.

17. Singh, A., Vishal, S., Goswami, A. (2015). Study of Genetic Parameters for Yield and Yield contributing Trait of Elite Genotypes of barley (Hordeum vulgare L.). Trends in Biosciences,8(4): 98-105.

18. Singh, S.K., Verma, P.N., Singh, L., Ali, T., Prasad, K.D. (2014). Variability and Divergence Analysis in Barley (Hordeum vulgare L.) under Irrigated Condition. Trends in Biosciences, 7 (6): 452-456.

19. Sivasubramanian, J., Madhavamenon, P. (1973). Genotypic and phenotypic variability in rice. Madras Agric. J.
12: $15-16$.

20. Sunil K.Y, Singh A.K., Pandey, P., Singh, S. (2015) Genetic Variability and Direct Selection Criterion for Seed Yield in Segregating Generations of Barley (Hordeum vulgare L.). American Journal of Plant Sciences, 6:1543-1549 .

21. Wolde, T., Firdisa, E., Sentayehu, A., Ermias, A.D. (2016). Genetic variability, heritability and genetic advance for yield and yield related traits in Durum wheat (Triticum durum L.) accessions. Sky Journal of Agricultural Research,5(3): 042 - 047.

\section{How to cite this article:}

Banoth Vinesh, L.C. Prasadand Ravindra Prasad. 2018. Variability and Diversity Studies in Exotic and Indigenous Barley (Hordeum vulgare L.). Int.J.Curr.Microbiol.App.Sci. 7(07): 2007-2019. doi: https://doi.org/10.20546/ijcmas.2018.707.237 